\title{
Perkhidmatan Kaunseling di Institusi Penjagaan Kesihatan: Isu dan Cabaran Kaunselor di Sarawak
}

\author{
Merikan Aren ${ }^{1}$, Faizah Abd Ghani ${ }^{2}$, Zainal Abidin Zainuddin ${ }^{3}$ \\ ${ }^{123}$ Universiti Teknologi Malaysia \\ $\risingdotseq$ e-mail: mbarsu64@yahoo.com
}

\begin{abstract}
Perkhidmatan kaunseling di Malaysia tidak hanya bertapak di institusi pendidikan tetapi telah berkembang dengan pesat di pelbagai agensi kerajaan dan swasta mulai 1990an dengan tertubuhnya Unit Psikologi dan Kaunseling oleh Jabatan Perkhidmatan Awam Malaysia. Perkhidmatan kaunseling di institusi penjagaan kesihatan adalah bertujuan untuk membantu klien memahami dan berupaya menghadapi perasaan dan emosi berkaitan dengan masalah kesihatan di samping membantu klien untuk berkembang serta memberi sokongan yang berterusan sepanjang proses rawatan. Kajian kualitatif ini bertujuan untuk mengenal pasti isu dan cabaran yang dihadapi oleh para kaunselor dalam melaksanakan perkhidmatan kaunseling di institusi penjagaan kesihatan. Dapatan kajian mendapati enam tema utama isu dan cabaran yang dihadapi oleh kaunselor iaitu peranan kaunselor (24.6\%), limitasi perkhidmatan (22.8\%) kelayakan kaunselor (19.3\%), aplikasi perkhidmatan kaunseling kesihatan (15.5\%), cadangan penambahbaikan (14\%) dan keperluan garis panduan (3.8\%). Seterusnya, kajian ini juga membincangkan implikasi kajian terhadap peranan, latihan dan aplikasi kaunseling kesihatan di institusi penjagaan kesihatan.
\end{abstract}

Keyword: kaunselor, kaunseling kesihatan, institusi penjagaan kesihatan \& isu dan cabaran

Copyright (C) 2017 IICET (Indonesia) - All Rights Reserved

Indonesian Institute for Counseling, Education and Therapy (IICET)

\section{PENDAHULUAN}

Perkhidmatan kaunseling di Malaysia telah mula diterima dan semakin diperlukan oleh masyarakat Malaysia hari ini. Perkembangan ini telah menunjukkan bahawa profesion kaunseling telah mula diiktiraf setanding dengan profesion lain seperti doktor, jurutera dan peguam (PERKAMA, 2010; Muhd. Mansur \& S. Nordinar, 2010). Kehidupan masyarakat yang semakin kompleks hari ini menyebabkan munculnya pelbagai masalah kehidupan yang boleh menjurus kepada masalah kesihatan mental dan juga penyakit kronik seperti diabetes, kanser, darah tinggi dan kardio-vaskular. Peningkatan jumlah penyakit kronik tidak berjangkit ini merupakan cabaran dan isu penting yang harus ditangani dengan segera. Sehubungan dengan itu, perkhidmatan kaunseling di Malaysia telah berkembang ke institusi penjagaan dan tidak lagi hanya bertapak di sekolah serta di institusi pengajian tinggi tetapi telah mula melebarkan perkhidmatan di pelbagai agensi kerajaan dan swasta dengan wujudnya Unit Psikologi dan Kaunseling yang diperkenalkan oleh Jabatan Perkhidmatan Awam pada awal tahun 1990an (Suradi \& Rafidah Aga, 2005).

Perkhidmatan kaunseling di institusi penjagaan kesihatan telah mula diperkenalkan pada awal tahun 1980an dengan menempatkan kaunselor di beberapa hospital dan hospital psikiatri. Pada awalnya perkhidmatan kaunseling lebih menumpukan perkhidmatannya kepada masalah kesihatan mental, HIV dan AIDS serta kaunseling berhenti merokok (Glamcevski, 2008; Ching \& Kok-Mun, 2010; Stockton, Nitza \& Bhusumance, 2010). Di Sarawak perkhidmatan kaunseling telah bermula di Hospital Sentosa Kuching iaitu hospital yang khusus merawat pesakit mental dan masalah kesihatan mental pada tahun 1980an. Sehingga tahun 2011 terdapat 103 orang kaunselor berkhidmat di Kementerian Kesihatan Malaysia (KKM) dan hanya 
tujuh orang kaunselor yang berkhidmat di seluruh negeri Sarawak (Unit Psikologi dan Kaunseling KKM, 2011).

Selaras dengan peningkatan jumlah pesakit kronik yang semakin meningkat menyebabkan permintaan perkhidmatan kaunseling di institusi penjagaan kesihatan semakin diperlukan. Pelbagai langkah telah dijalankan oleh kerajaaan seperti kempen cara hidup sihat tetapi kejadian berbagai jenis penyakit kronik masih tidak dapat dibendung dengan jayanya di mana dijangka 2/3 penduduk Malaysia akan mengalami masalah penyakit kronik (Zafar, Noraini \& Ambar, 2005). Justeru itu, peranan kaunselor dilihat semakin diperlukan khususnya dalam kaunseling kesihatan. (Glamcevski, 2008). Sehubungan dengan itu, kepakaran dan pengkhususan kaunselor sangat diperlukan bagi menyediakan perkhidmatan kaunseling yang profesional selaras dengan yang disarankan oleh Honskin dan Thomson (2009) yang menyatakan bahawa perkembangan profesion kaunselor hendaklah berteraskan pengetahuan, sikap dan keperluan kemahiran yang khusus seperti mana yang diperlukan oleh klien pada masa sekarang.

Walaupun perkembangan perkhidmatan kaunseling semakin penting namun perkhidmatan kaunseling di Malaysia juga menghadapi cabaran dalam membangunkan profesion kaunselor terutama dalam aspek memberi latihan dan perkhidmatan serta untuk mencapai profesional identiti. Mengikut Unit Pengurusan Pengajian Tinggi Kementerian Pengajian Tinggi pada tahun 2011 terdapat 11 buah universiti awam yang menawarkan kursus kaunseling sama ada di peringkat ijazah atau pasca ijazah (Unit Pengurusan Universiti, 2011). Kebanyakan latihan asas kaunseling yang ditawarkan oleh institusi-institusi ini adalah berkaitan dengan kaunseling psikologi, kaunseling organisasi, kaunseling pencegahan dadah serta program bimbingan dan kaunseling untuk sekolah. Sementara itu, perlantikan kaunselor yang berkhidmat di institusi penjagaan kesihatan adalah berdasarkan kelayakan akademi latihan asas kaunseling di mana kaunselor harus memiliki sama ada ijazah sarjana muda, sarjana atau doktor falsafah (PhD) dalam bidang kaunseling, psikologi dan klinikal psikologi. (Pekeliling Perkhidmatan Awam Bil.29, 2007).

Menurut statistik 2011 Unit Psikologi dan Kaunseling Kementerian Kesihatan Malaysia daripada 103 orang kaunselor yang berkhidmat di Kementerian Kesihatan Malaysia, 65 orang dari kaunselor ini berkhidmat di institusi penjagaan kesihatan iaitu di hospital dan di hospital psikiatri (Unit Psikologi dan Kaunseling, KKM, 2011). Kekurangan kaunselor yang berkhidmat di institusi penjagaan kesihatan ditahun-tahun sebelum ini menyebabkan Kementerian Kesihatan Malaysia telah melatih 44 orang fasilitator dalam kaunseling kesihatan mental dan menubuhkan 129 pusat kaunseling kesihatan mental di seluruh negara pada tahun 1999 (Glamcevski, 2008). Perkhidmatan kaunseling yang ditawarkan adalah perkhidmatan seperti kaunseling pemulihan psikososial, pengurusan diri, kesihatan mental dan latihan kemahiran hidup. Selain itu, menurut Stockton, Nitza dan Bhusumance (2010), kompentesi kaunselor yang menjalankan perkhidmatan kaunseling di institusi penjagaan kesihatan belum lagi mencapai tahap yang memuaskan kerana tidak mempunyai kepakaran yang profesional di mana kebanyakan kaunselor yang berkhidmat di institusi penjagaan kesihatan mempunyai latihan yang terhad. Palmaer dan Bor (2008) pula mengatakan bahawa adalah sangat penting bahawa pengamal kaunseling yang tidak berkelayakan tidak boleh melakukan perkara di luar bidang latihan dan kepakaran mereka seperti menjalankan sesi kaunseling bagi memastikan pesakit atau klien mendapat perkhidmatan yang sempurna.

Keperluan pengetahuan dan kemahiran dalam bidang kaunseling kesihatan sangat penting kerana bukan semua pesakit yang datang menerima rawatan memerlukan rawatan perubatan sesetengah pesakit yang datang memerlukan rawatan secara psikologi dan emosi (Muhd. Mansur \& S. Nordinar, 2010). Doka (2009), menyatakan bahawa bermula dari masa didiagnosis dan sepanjang masa rawatan dan pemulihan pesakit akan mengalami pelbagai keadaan yang tidak menentu seperti bagaimana hendak memenuhi tuntutan kehidupan harian, menghadapi simptom penyakit dan kesan sampingan dari rawatan yang diterima yang mana kepayahan ini bukan hanya dihadapi oleh pesakit tetapi juga melibatkan ahli keluarga pesakit. Dengan adanya kaunselor di institusi penjagaan kesihatan akan dapat membantu pesakit dalam menghadapi permasalahan keluarga, imej diri, perkembangan kerjaya dan masalah psikososial serta membantu dalam pencegahan dan pemulihan penyakit. Oleh yang demikian, Ethrington (2002) menyarankan agar setiap institusi penjagaan kesihatan mempunyai kaunselor yang terlatih dalam bidang kaunseling berdasarkan perkhidmatan yang ditawarkan.

Dengan wujudnya Unit Psikologi dan Kaunseling di institusi penjagaan kesihatan di Malaysia dilihat sebagai titik tolak ke arah perkhidmatan kaunseling yang lebih profesional. Walau bagaimanapun, perkhidmatan yang ditawarkan adalah agak terhad dan lebih tertumpu kepada aktiviti yang berkaitan dengan 
perkembangan staf seperti memberi latihan dan motivasi serta kaunseling untuk staf yang mempunyai masalah disiplin dan berprestasi rendah berbanding menjalankan perkhidmatan kaunseling kepada pesakit dan keluarga pesakit. Ini adalah disebabkan oleh ketiadaan kemahiran dan pengetahuan dalam bidang kesihatan dan perubatan menyebabkan para kaunselor merasa tidak layak dan tidak selesa untuk menjalankan kaunseling terhadap kes yang mempunyai masalah kesihatan dan perubatan (Merikan, Faizah \& Zainal Abidin, 2011).

Peningkatan masalah psikososial di Malaysia telah didapati memberi kesan yang mendalam kepada masalah kesihatan masyarakat di Malaysia. Dengan itu, perkhidmatan tolong bantu yang profesional seperti perkhidmatan kaunseling semakin diperlukan (Ching \& Kok-Mun, 2010). Memandangkan tidak terdapatnya institusi latihan kaunselor atau satu model khusus bagi melatih kaunselor yang berkhidmat di institusi kesihatan maka Glamcevski (2010), menyarankan agar diadakan satu model kaunseling yang sesuai untuk membantu rakyat Malaysia dalam menangani masalah kesihatan mental selain daripada itu juga Ching dan Kok_Mun (2010) menyatakan bahawa satu usaha mesti dijalankan bagi memastikan bahawa semua kaunselor mempunyai kompetensi untuk membekalkan perkhidmatan tolong bantu yang efektif dalam bidang yang khusus seperti kaunseling HIV/AIDS, drug, seksual, kesihatan mental dan kaunseling keluarga. Selain itu, Glamcevski (2010) juga menyarankan agar suatu garis panduan atau model yang lebih sesuai dengan perkhidmatan yang ditawarkan dibentuk bagi memastikan perkhidmatan kaunseling yang ditawarkan memberi manfaat kepada klien atau pesakit.

Cabaran lain yang dihadapi oleh kaunselor di institusi penjagaan kesihatan juga ialah persaingan siapakah yang layak untuk menjalankan kaunseling kepada pesakit kerana mengikut AKTA 580, Akta Kaunselor 1998 membenarkan para profesional kesihatan atau mana-mana syarikat, pertubuhan atau pihak berkuasa tempatan yang memberi jagaan kesihatan boleh menjalankan kaunseling tanpa wajib berdaftar dengan Lembaga Kaunselor Malaysia.Walau bagaimanapun menurut Naslindh-Ylispangar, Silvonen, Saran dan Kekki (2008) mendapati bahawa pakar perubatan dan jururawat kesihatan awam serta para pembekal penjagaan kesihatan tidak mempunyai kompeten dalam membuat sesi kaunseling selain memerlukan latihan terutama dari segi pengisian dan pendekatan yang boleh digunakan dalam kaunseling kesihatan. Selain itu, para staf kesihatan juga menghadapi kekangan masa dan mempunyai tugas hakiki lain yang lebih utama menyebabkan sesi kaunseling tidak begitu efektif dan kurang mendapat sambutan daripada pesakit.

Memandangkan perkhidmatan kaunseling yang khusus seperti bidang kaunseling kesihatan semakin diperlukan maka kajian ini akan mengenal pasti isu dan cabaran yang dihadapi oleh kaunselor bagi membantu para kaunselor di institusi penjagaan kesihatan bagi memberikan perkhidmatan kaunseling yang lebih relevan dan mempunyai halatuju selain daripada meningkatkan lagi kualiti perkhidmatan dan pembangunan profesion kaunseling di Malaysia.

Secara umum kajian ini bertujuan untuk mengenal pasti isu dan cabaran yang dihadapi oleh para kaunselor di Sarawak dalam melaksanakan perkhidmatan kaunseling di institusi penjagaan kesihatan.

\section{METODOLOGI}

Kajian ini adalah berbentuk kualitatif dengan menggunakan kaedah temuduga semi strtuktur yang melibatkan lima orang ketua jabatan atau penyelia yang mempunyai kaitan secara lansung dengan aktivitiaktiviti perkhidmatan kaunseling di institusi penjagaan kesihatan di Sarawak. Kajian ini juga melibatkan lima orang kaunselor yang sedang berkhidmat di institusi penjagaan kesihatan sebagai responden dengan menggunakan soal selidik secara soalan terbuka di mana 15 persoalan berkaitan perlantikan, latihan, pembangunan profesional, peranan, tugas utama, pengendalian kes, jenis kes, pendekatan kaunseling, pengalaman mengendalikan kes, mengurus kes rujukan, penyeliaan, garis panduan, limitasi dan pendapat tentang aplikasi perkhidmatan kaunseling kesihatan serta menyatakan komen tentang perkhidmatan yang yang dijalankan. Responden dikehendaki menulis jawapan dan pandangan mereka pada ruang yang disediakan.

Responden kajian ini adalah merupakan sampel bertujuan bagi memastikan matlamat kajian tercapai di mana sampel kaunselor terdiri daripada tiga orang perempuan dan dua orang lelaki manakala ketua jabatan atau penyelia pula terdiri dari tiga lelaki dan dua orang perempuan yang terdiri daripada Pakar kesihatan Awam dan keluarga, Ketua Penyelia Penolong Pegawai Perubatan, Ketua Penyelia Jururawat dan Pengajar Penolong Pegawai Perubatan Kanan. Semua sesi temuduga telah dirakam dengan keizinan responden dan dijadikan transkrip untuk dianalisis dengan menggunakan QSR Nvivo 8. Selain itu analisis secara deskriptif juga dilakukan bagi menentukan tema untuk tujuan laporan kajian. 


\section{HASIL DAN PEMBAHASAN}

Hasil dapatan kajian mendapati terdapat enam tema utama yang menjadi isu dan cabaran yang dihadapi oleh kaunselor yang berkhidmat di institusi penjagaan kesihatan iaitu peranan kaunselor (24.6\%), limitasi perkhidmatan (22.8\%) kelayakan kaunselor (19.3\%), aplikasi perkhidmatan kaunseling kesihatan $(15.5 \%)$, cadangan penambahbaikan perkhidmatan (14\%) dan keperluan garis panduan $(3.8 \%)$.

\section{Peranan Kaunselor}

Kaunseling kesihatan merupakan sebagai satu bidang pengkhususan boleh memainkan tugas sebagai pelangkap dalam meningkatkan mutu kesihatan secara menyeluruh (Abdul Halim, 2000). Keseluruhan responden dalam kajian ini bersetuju bahawa jawatan kaunselor di institusi penjagaan kesihatan adalah sangat penting dan sangat diperlukan kerana pesakit memerlukan bimbingan, sokongan dan bantuan dalam penyelesaiaan masalah. Perkhidmatan ini sangat wajar ditawarkan di institusi penjagaan kesihatan dan sepatutnya telah disediakan sejak dahulu lagi di setiap institusi penjagaan kesihatan. Ini adalah kerana menurut responden pemulihan secara perubatan adalah tidak mencukupi kerana tidak semua pesakit yang datang memerlukan ubat-ubatan tetapi terdapat juga pesakit yang memerlukan rawatan psikologi dan emosi. Manakala tiga peranan utama kaunselor di institusi penjagaan kesihatan ialah menjalankan khidmat kaunseling, menjalankan aktiviti bimbingan dan latihan untuk staf kesihatan dan menjalankan kerja-kerja pengurusan dan pentadbiran. Manakala bidang kaunseling yang ditawarkan ialah kaunseling individu dan kelompok, bimbingan dan latihan kerjaya serta menjalankan psiko-pendidikan dan kaunseling keluarga.

Kedua-dua kumpulan responden kajian menyatakan klien utama yang menggunakan perkhidmatan kaunselingdi institusi penjagaan kesihatan ialah staf kesihatan, pesakit dan ahli keluarga pesakit. Walau bagaimanapun, masih ramai anggota kesihatan dan kaunselor yang masik tidak tahu dan jelas peranan sebenar kaunselor di institusi penjagaan kesihatan dan ini menyebabkan kurangnya rujukan dilakukan oleh pegawai perubatan seperti mana dijelaskan oleh P001 "not clear actually on what they are supposed to do" dan kenyataan ini disokong oleh P004 yang menyatakan "peranan kaunselor lebih kepada memberi nasihat". Bagi P005 pula dia melihat peranan kaunselor sebagai "orang bertanggungjawab mengendalikan beberapa kursus untuk staf dan pelajar".

Selain itu, peranan kaunselor di institusi penjagaan kesihatan adalah untuk mengendalikan kursus motivasi dan bimbingan untuk staf di samping mengendalikan sesi ceramah untuk program Perkembangan Profesional Berterusan (CPD) serta memberi bimbangan kepada pesakit berbentuk psiko-pendidikan. Walau bagimanapun menurut PP002 menyatakan "saya ada ikut dia orang bagi psycho-education tapi bagi kami lihat ianya tidak berkesan, tak confident, dan ada juga salah information....”. Bagi memantapkan peranan kaunselor di institusi penjagaan kesihatan para kaunselor hendaklah memiliki latar belakang dalam bidang perubatan dan kesihatan seperti dinyatakan oleh PP003 “ sebab patient sekarang they more better than us, they read from internet if tomorrow they want to see us, before they come to see us they read first. He will question you, if you don't have enough knowledge, how to answer him back. Mereka lebih advanced, they equip them self'.

Dapatan kajian ini adalah selaras dengan dapatan kajian oleh Purcell dan Vallis (2005) bertajuk profesional kaunseling kesihatan untuk sokongan perubahan tingkah laku di Pusat Penjagaan Kanser Nova Scotia dalam pencegahan kanser yang mendapati bahawa staf yang aktif menjalankan aktiviti kaunseling kepada pesakit menyatakan peningkatan keyakinan dan kemahiran dalam kaunseling dan dapat mempengaruhi perubahan tingkah laku pesakit dalam masa yang singkat. Oleh itu, jika kaunselor sentiasa mengamalkan amalam kaunseling yang baik dan selalu berhadapan dengan isu dan permsalahan berkaitan perubatan dan kesihatan sudah tentu mereka akan jadi mahir dan cekap dalam menjalankan sesi kaunseling di masa akan datang. Maka adalah perlu kaunselor memainkan peranannya selaras dengan tuntutan di mana mereka ditempatkan untuk berkhidmat.

\section{Limitasi Perkhidmatan}

Keseluruhan responden menyatakan terdapat limitasi yang dihadapi oleh kaunselor di mana kebanyakan responden yang bertugas di institusi penjagaan kesihatan adalah secara bersendirian dan mereka menghadapi beban tugas yang agak berat. Di samping itu kaunselor yang baru bertugas terutamanya tidak mempunyai pengalaman dan latihan akan menghadapi kesukaran apabila berhadapan dengan kes yang berkaitan dengan isu perubatan dan kesihatan. Keadaan ini sungguh mencabar dan menjadikan mereka tidak yakin dalam mengendalikan kes-kes rujukan. Para kaunselor menyatakan mereka lebih yakin untuk mengendalikan klien 
dari kalangan anggota kesihatan berbanding pesakit kerana isu yang dibincangkan lebih menjurus kepada masalah kerja, hubungan, disiplin dan masalah kesihatan mental seperti stress, kebimbangan dan depresi.

Selain itu, kedua-dua kumpulan responden menyatakan bahawa kaunselor di institusi penjagaan kesihatan tidak mempunyai bilik yang sesuai untuk sesi kaunseling kerana berkongsi dengan anggota kesihatan yang lain menyebabkan tiada privasi di samping terdapat anggota kesihatan sendiri yang tidak memahami proses kaunseling. Serlain itu aktiviti kaunseling kurang menyerlah dan tidak diketahui umum khususnya para medik dan professional kesihatan menyebabkan kurang rujukan dan peranan kaunselor kurang diketahui. Tidak ada promosi dijalankan seperti mana dikatakan oleh PP001 menyatakan "kita rasa aktiviti kaunseling tidak aktif, tidak giat..." dan beliau juga mengharapkan kaunselor boleh menawarkan peranan mereka melalui mesyuarat pagi yang dijalankan di setiap hospital atau melalui aktiviti Continues Medical Development (CME). Para kaunselor juga dikatakan menghadapi masalah untuk mengikuti program di institusi penjagaan kesihatan terutama aktiviti berbentuk kemasyarakatan kerana kebanyakan mereka hanya seorang dan tidak ada pembantu. Ini akan menyukarkan pergerakan mereka dan keadaan ini menyebabkan peranan kaunselor tidak menyerlah dan kurang difahami oleh masyarakat.

Stigma masyarakat juga merupakan salah satu kekangan yang dihadapi oleh kaunselor kerana mereka tidak mahu jumpa kaunselor disebabkan rasa malu dan takut kerana pada anggapan mereka apabila seseorang itu berjumpa kaunselor mereka telah mempunyai masalah kesihatan jiwa dan ini menyebabkan kebanyakan yang hadir terdiri dari ahli keluarga berbanding dengan pesakit. Selain itu pengetahuan dalam bidang perubatan dan kesihatan amat perlu memandangkan tidak terdapat latihan khusus untuk kaunselor dalam bidang kesihatan dan perubatan sebelum mereka ditempatkan di institusi penjagaan kesihatan. Menurut PP002 "dari segi effectiveness ya lebih baik kalau ada backgraound kesihatan..... so sekarang ni kaunselor yang dilantik di sini ialah mempunyai basic kaunseling sahaja .. and then, in term of medical background memang tak ada". Selain itu PP004 menyatakan bahawa mereka perlu dihantar menghadiri kursus "kursus yang melibatkan lebih kepada masalah-masalah kesihatanlah, macam mental health, kaunseling diabetes, hypertension, kardiavaskular, social psikologi dan banyak lagi”. Manakala PP003 menyarankan agar diadakan latihan setempat seperti penempatan di Jabatan Pesakit Luar dan Klinik Psikiatri supaya mereka mengetahui tanda-tanda dan symptom-simptom penyakit serta rawatan serta terminologi yang digunakan dalam perubatan. Kenyataan ini disokong oleh Hooper dan Weitz (2006), yang menegaskan bahawa kaunselor sepatutnya memberi perkhidmatan dan penjagaan yang berkualiti untuk pesakit sebaik sahaja mereka masuk ke institusi penjagaan kesihatan. Justeru itu, kaunselor harus mempunyai kecekapan yang profesional supaya dapat menyumbang perkhidmatan yang berkualiti.

\section{Kelayakan Kaunselor}

Kelayakan akademi merupakan salah satu syarat utama dalam perlantikan seseorang anggota kerajaan. Bagi jawatan Pegawai Psikologi atau lebih dikenali sebagai kaunselor kelayakan minimum adalah memiliki ijazah sarjana muda kaunseling, psikologi atau psikologi klinikal. Hasil dapatan kajian mendapati kesemua responden kaunselor memiliki kelayakan yang diiktiraf oleh Jabatan Perkhidmatan Awam Malaysia (JPA) namun hanya empat orang sahaja yang telah berdaftar dengan Lembaga Kaunselor Malaysia dan hanya seorang sahaja yang mempunyai Sijil Akuan Amalan. Mengikut Akta 580 Akta Kaunselor 1998 setiap pengamal kaunseling harus berdaftar dengan lembaga dan mempunyai Sijil Akuan Amalan. Berdasarkan kenyataan yang diperolehi juga mendapati hanya 2 orang kaunselor yang mempunyai pengalaman latihan praktikal semasa latihan asas di hospital dan dua orang juga memohon untuk ditempatkan berkhidmat di institusi penjagaan kesihatan. Walau bagaimanapun keseluruhan responden penyelia menyatakan bahawa kelima-lima kaunselor adalah mempunyai kemahiran asas kaunseling yang boleh diaplikasikan ke atas perkhidmatan kaunseling yang ditawarkan di mana keseluruhan kaunselor menyatakan bahawa mereka merasa kemahiran sedia ada sesuai tetapi 2 orang daripada mereka mengatakan mereka tidak layak untuk menjalankan kaunseling di institusi kesihatan. Selain itu, tiga orang kaunselor juga menyatakan mereka tidak selesa untuk menjalankan kaunseling untuk kes-kes yang berkaitan dengan isu kesihatan dan perubatan. Keseluruhan responden bersetuju bahawa kaunselor yang berkhidmat di institusi penjagaan kesihatan memerlukan latihan khusus dalam bidnag kaunseling kesihatan.

Walau bagaimanapun responden penyelia menyatakan jika mereka tiada latihan asas dalam bidnag kesihatan atau perubatan kaunselor hendaklah dilatih secara "in house training" atau ditempatkan di Jabatan Pesakit Luar, atau mana-mana wad berkaitan seperti Wad Radio Terapi dan Klinik Psikiatri bagi mempelajari pelbagai jenis penyakit dan rawatan serta jenis ubat-ubatan yang digunakan serta komplikasi rawatan dan 
sebagainya. Menurut responden penyelia para kaunselor harus tahu terminologi dan prosidur untuk setiap jenis kes penyakit. Ini akan lebih memberi kepercayaan kepada pekerja kesihatan yang lain untuk bekerjasama dalam pemulihan penyakit seperti membuat rujukan kepada kaunselor jika pesakit memerlukan perkhidmatan kaunseling. Responden penyelia PP004 menyatakan "sekarang ini orang banyak menggunakan terminology dah... ada stage 1 , stage 2 , stage 3 , stage 4 .. kalau kaunselor tak faham apa itu stage $1,2,3,4 \ldots$. Katakanlah pesakit datang dia bagi tahu, saya stage 4 ni, kalau kaunselor blur-blur, macamana nak memberi kaunseling?" dan ini disokong oleh PP005 yang mengatakan "kalaulah boleh mereka (kaunselor) ini ditambah dengan sedikit pengetahuan tentang anatomi fisiologi, bagaimana berlakunya punca penyakit itu saya rasa adalah bonus untuk kaunselor kesihatan”.

Selain itu responden penyelia juga menyatakan bahawa adalah lebih baik jika perlantikan kaunselor di institusi penjagaan kesihatan terdiri daripada mereka yang mempunyai latihan dalam bidang perubatan dan kesihatan seperti memberi latihan "upgrading" atau kursus penigkatan untuk para anggota kesihatan seperti Penolong Pegawai Perubatan dan Jururawat dalam bidang kaunseling bagi menyediakan kaunselor yang lebih berkelayakan untuk berkhidmat di institusi penjagaan kesihatan. Dapatan ini selari dengan kenyataan oleh Muhd. Mansur dan S. Nordinar, (2010) yang menyatakan bahawa sewajarnya mereka yang terlibat dalam kaunseling merupakan orang-orang yang terlatih supaya dapat memperlihatkan mutu perkhidmatan profesional yang terpuji.

\section{Aplikasi Perkhidmatan Kaunseling Kesihatan}

Berdasarkan dapatan kajian mendapati tidak semua institusi penjagaan seperti hospital mempunyai kaunselor. Oleh yang demikian kebanyakan perkhidmatan kaunseling dijalankan oleh para medik atau anggota kesihatan. Oleh yang demikian aplikasi kaunseling kesihatan belum dijalankan sepenuhnya oleh kaunselor yang terlibat disebabkan tiada latihan asas dalam bidang kaunseling kesihatan dan keseluruhan para kaunselor menyatakan bahawa amalan kaunseling yang mereka praktikan adalah berdasarkan kemahiran asas kaunseling yang diaplikasikan mengikut jenis kes dan mereka menyatakan pendekatan kaunseling yang biasa digunakan adalah pendekatan pencegahan, pendekatan pemulihan dan pendekatan perkembangan dan pendekatan krisis.

Selain itu responden kaunselor juga menyatakan bahawa mereka mempunyai kesukaran dalam mengendalikan rekod dan laporan sesi kaunseling selain mengalami kesukaran untuk mencapai piawai yang ditetapkan kerana tidak pernah melalui latihan khusus dalam pengendalian kes berkaitan perubatan dan kesihatan. Selain itu, pengurusan kes yang dirujuk juga merupakan masalah yang dihadapi oleh para kaunselor kerana kebanyakan kes adalah di luar jangka dan mempunyai isu-isu yang saling berkaitan dengan kes perubatan dan kesihatan. Oleh yang demikian, keseluruhan responden penyelia menyatakan bahawa kaunselor sepatutnya tidak menunggu rujukan dari pegawai perubatan atau mana-mana anggota kesihatan tetapi para kaunselor sepatutnya turut sama dalam pasukan pemulihan semasa waktu pemeriksaan dan penilaian pesakit setiap kali dijalankan (ward round) bagi memastikan apa masalah yang harus diambil tindakan dalam pendekatan kaunseling terhadap pesakit mengikut hasil perbincangan pasukan. Ini akan memudahkan proses kaunseling yang akan dijalankan kerana masalah yang dihadapi oleh pesakit telah dikenal pasti secara bersama dan perancangan intervensi melalui kaunseling boleh dilaksanakan dengan lebih mudah. Bagi perlaksanaan aplikasi kaunseling di institusi penjagaan kesihatan keseluruhan responden penyelia belum berpuashati dengan perkhidmatan yang diberikan oleh kaunselor dimana purata pencapaian tahap kepuasan mereka adalah 5.4 dari skala 1 hingga 10 di mana 1 adalah sangat tidak memuaskan dan 10 adalah sangat memuaskan. Dapatan kajian adalah selaras dengan kenyataan oleh Hooper dan Weitz (2006), yang mengatakan bahawa kaunselor sepatutnya menyediakan tempat yang selesa, memastikan tiada gangguan semasa sesi dijalankan, melayani pesakit dengan adil dan saksama serta menepati temu janji. Justeru itu, kaunselor di institusi penjagaan kesihatan seharusnya boleh mengaplikasikan pendekatan kaunseling yang selaras dengan keperluan dan permintaan organisasi supaya perkhidmatan yang ditawarkan boleh mencapai objektif dan tujuannya.

\section{Cadangan Penambaikan}

Pelbagai cadangan telah disyorkan oleh responden bagi menambah baik perkhidmatan kaunseling di institusi penjagaan kesihatan. Antaranya ialah berkaitan perlatikan kaunselor di mana mereka menacadangkan agar kaunselor yang hendak berkhidmat di institusi penjagaan kesihatan harus mempunyai pengetahuan berkaitan penyakit, rawatan dan komplikasi penyakit serta kaedah pencegahan dan sebagainya dengan cara memberi latihan jangka pendek seperti penempatan di Jabatan Pesakit Luar (OPD), Wad Kanser atau Unit 
Radio Terapi, di wad Perubatan dan Klinik Psikiatri. Para kaunselor juga boleh menambah pengetahuan melalui sesi CME atau CPD. Responden penyelia keseluruhannya mencadangkan agar diadakan kursus pengkhususan atau kepakaran seperti "Post Basic Training" yang dilaksanakan oleh KKM kepada para kaunselor seperti mana para medik yang mempunyai pilihan kursus "post-basic" dalam bidang tertentu selama enam bulan hingga satu tahun. Kenyataan ini disokong oleh PP 003 yang menyatakan "kalau ada background medical lagi bagus, if you have knowledge you confident to talk... kalau tak tahu tentang penyakit susah .. dia akan lebih mudah menerangkan tentang penyakit like HIV kalau tak tahu macam mananak terang pasal penyakit, must know the impact about HIV/AIDS...".

Selain itu juga, responden penyelia mencadangkan agar kaunselor berada di wad-wad tertentu secara berjadual agar rujukan pesakit mudah di lakukan selain daripada pesakit hadir dengan sukarela untuk mendapat perkhidmatan kaunseling. Penyelia juga mencadangkan agar kaunselor mengikuti pasukan perubatan semasa "round ward" agar mudah mengenali keperluan pesakit dari segi psikologi dan emosi. Pendekatan "out-reach" juga dicadang agar pesakit mendapat perkhidmatan yang sebaiknya sama ada sebagai pesakit dalam (in-patient)" atau pesakit luar (out patient) ataupun menziarahi pesakit melalui program perkhidmatan komuniti. Seperti mana yang dinyatakan oleh PP001 "kami rasa kaunselor perlu ada ikut dalam CPN untuk kemudahan dan kebaikan patient and relatives". Dapatan kajian ini sesuai seperti mana yang dinyatakan oleh Muhd. Mansur dan S. Nordinar, (2010a) yang mengatakan bahawa kaunselor harus melakukan program "out-reach" dalam kaunseling untuk semua seting yang melibatkan aneka teori, teknik termasuk pendidikan psikologi, pendekatan holistik, program mencegah kesihatan serta meningkatkan lagi program-program intervensi krisis. Hal ini boleh menjadikan kaunselor semakin diperlukan, dikenali dan semakin ramai orang mengkehendaki perkhidmatan kaunseling dan menjadi rujukan

Selain itu, responden penyelia juga mencadangkan agar jawatan kaunselor diperbanyakkan dan seharusnya setiap hospital mempunyai sekurang-kurangnya seorang kauselor seperti yang dinyatakan oleh PP004 "kita perlu buka lebih banyak lagi jawatan-jawatan di hospital-hospital dan juga klinik-klinik kesihatan... jadi, peranan yang dimainkan lebih baiklah". Oleh itu, selaras dengan saranan yang dinyatakan oleh Calzone, Prindiville, Jourkiv, Jerkins et al. (2005), bahawa kaunselor di institusi penjagaan kesihatan tidak seharusnya bergantung kepada pengetahuan dan kemahiran asas kaunseling sahaja tetapi harus perlu mengembangkan kemahiran dan pengetahuan selaras dengan perkembangan semasa - Evidence based counselling.

\section{Keperluan Garis Panduan}

Dapatan kajian juga mendapati kedua-dua kumpulan respoden bersetuju bahawa kaunselor mempunyai garis panduan yang piawai bagi menentukan jenis perkhidmatan kaunseling yang dijalankan, jenis klien dan permasalahan yang dihadapi serta intervensi selain daripada kaedah pengurusan rekod dan rujukan. Ini adalah penting bagi mengelak perkara yang di luar batasan bidang dan tidak menyalahi etika kaunseling dan prosidur rawatan dan pengurusan pesakit. Pada masa sekarang keseluruhan kaunselor bergantung kepada surat pekeliling dari Kementerian Kesihatan Malaysia dan Jabatan Perkhidmatan Awam selain daripada fail meja dan manual prosidur kerja sebagai panduan dalam memberi perkhidmatan kepada pesakit. Responden penyelia PP005 menyatakan "wajar dapat dirangka satu garis panduan menjalankan tugas yang lebih terperincilah supaya mereka menjalankan tersebut dan tidak terkeluar dari apa yang seharusnya dan yang sepatutnya mereka lakukan. Saya rasa garispanduan itu penting untuk dikaji dan dilihat semula”.

Dapatan kajian menunjukkan cadangan yang dikemukakan oleh responden adalah sesuai untuk meningkatkan profesionalisme kaunselor selaras dengan kenyataan Velleman dan Aris (2010), yang menyatakan bahawa kaunseling melibatkan pemilihan pendekatan, teknik dan kemahiran yang tepat yang sesuai dengan situasi seperti bagaimana, untuk siapa dan bila masalah itu sesuai diperlukan. Latihan yang mencukupi dapat memberi keyakinan dan kecekapan. Kenyataan ini disokong oleh Jordans, Keen, Pradhan dan Tol (2007), yang mendapati bahawa lima bidang utama dalam melatih kaunselor iaitu berkaitan dengan tempoh, model latihan, kemahiran asas mikro kaunseling, penyeliaan dan praktikal personal terapi serta sensitiviti budaya. Sehubungan dengan itu, maka, garis panduan dan latihan yang tepat dan sesuai dengan perkhidmatan yang ditawarkan adalah sangat diperlukan oleh kaunselor yang berkhidmat di institusi penjagaan kesihatan. 


\section{SIMPULAN}

Keseluruhan responden dalam kajian ini menyatakan bahawa peranan kaunselor di institusi penjagaan kesihatan adalah sangat penting dan semakin diperlukan. Walau bagaimanapun kaunselor yang sedia ada masih mempunyai limitasi atau kekangan dalam menjalankan perkhidmatan kaunseling disebabkan tiada latihan khusus dalam bidang kaunseling kesihatan disamping tidak mempunyai pengetahuan yang mendalam dalam isu dan permasalahan berkaitan perubatan dan kesihatan. Ketiadaan garis panduan yang piawai menyebabkan perkhidmatan kaunseling kesihatan tidak diaplikasi sepenuhnya oleh kaunselor dan kerana itu mereka lebih selesa menjalankan kaunseling untuk staf kesihatan berbanding dengan pesakit. Keseluruhan responden bersetuju bahawa perlu diwujudkan satu garis panduan untuk perkhidmatan kaunseling di institusi penjagaan kesihatan supaya perkhidmatan itu dapat dipromosi dan ketengahkan dengan lebih luas lagi selaras dengan perkhidmatan kesihatan yang lain. Oleh itu, responden juga mencadangkan agar beberapa pendekatan perlu dilakukan bagi memperluaskan skop perkhidmatan kaunseling di institsui penjagaan kesihatan seperti menyertai pasukan pemulihan dalam aktiviti "out-reach" dan "ward round" serta aktiviti komuniti dan kemasyarakatan seperti Community Psychiatric Nursing (CPN) dan lain-lain. Keseluruhan hasil dapatan kajian telah dapat menjelaskan isu dan cabaran yang dihadapi oleh kaunselor yang sedang berkhidmat di institusi penjagaan kesihatan di Sarawak.

\section{DAFTAR RUJUKAN}

Abdul Halim Othman (2000). Kaunseling untuk kesejahteraan Insan: Satu Pengalaman di Malaysia, Siri Pidato Inaugural Universiti Malaysia Sabah, Kota kinabali: Universiti Malaysia Sabah.

Calzone, K.A., Prindville, S.A, Jourkiv, O., Jenkins, J. Et al. (2005). Randomized Comparison Of Group Versus Individual Genetic Education And Counselling for Familial Breast and/Or Ovarian Cancer. Journal Of Clinical Oncology, 23:15

Ching, M.S \& Kok-Mun, N. (2010). Counseling in Malaysia: History, Current Status and Future Trends. Journal of Counseling \& Development, 88, 18-22.

Doka, K.J. (2009). Counseling individual with life-threatening illness. New York: Springer Publishing Company.

Etherington, K. (2002). Rehabilitation Counselling in Physical and Mental Health. London: Jessica Kingsley Publishers.

Glamcevski,M. (2008). The Malaysian Counselling Profession, History and Brief Discussion of the Future, Counselling, Psychotherapy, and Health, 4 (1), Counselling

Hooper, D \& Weitz, P.,(2006). Psychological Therapies in Primary Care. London: Bristish Library Cataloging in Publication Data.

Hoskin, W.J. \& Thompson, H.C. (2009). Promoting International Counseling Identity: The role of collaboration, research, and training. Paper based on a program presented at the Amereican Counseling Association Annual Conference and Exposition, Charlotte, North Carolina.

Jabatan Perkhidmatan Awam Malaysia (2007). Pekeliling Perkhidmatan Awam Bil.27 2007.

Jordans, M.J., Keen, A.S. Pradhan, H., \& Tol, W.A. (2007). Psychosocial counselling in Nepal: Perspective of counsellors and beneficiaries. International Journal Advance counselling, 29:57-68.

Lembaga Penyelidikan Undang-Undang (2003). Akta Kaunselor 1998 (Akta 580) dan peraturanperaturan.Selangor: International Law Book Services.

Muhd. Mansur Abdullah \& S. Nordinar Mohd Tamin (2010). Proses kaunseling ( ${ }^{\text {rd }}$ Ed.) Kuala Lumpur: Dewan Bahasa dan Pustaka.

Muhd. Mansur Abdullah \& S. Nordinar Mohd Tamin (2010a). Pengantar Kaunseling (2 ${ }^{\text {nd }}$ Ed.) Kuala Lumpur: Dewan Bahasa Dan Pustaka

Naslindh-Ylispangar, A., Sihvonen,M, Sarna, S., Kekki, P. (2008). Health status, symptoms and health counselling among middle-aged: comparison of men at low and high risk. Journal compilation; Nordic College of caring Science.

Persatuan Kaunseling Malaysia (2010). Latar belakang Kaunseling Malaysia. Jurnal PERKAMA Jld 16. Kuala Lumpur. Persatuan Kaunseling Malaysia.

Palmer,S. \& Bor, R. (2008). The practitioners Handbook. A guide for counsellors, psychotherapies and counseling psychologies. London: SAGE.

Purcell, J., Piccinini, H. Dan Vallis, M. (2005). Health Professional counselling to support bahavior change . Physical activity: Let's get moving. Cancer Information For Primary Caregiver In Practice, 2

Stockton,R., Nitza, A. And Bhusumance, D.B. (2010). The development of professional Counseling in Botswana. Journal of Counseling \& Development, 88, 9 -12. 
Suradi Salem \& Rafidah Aga Mohd Jaladin (2005). Development of counseling service in Malaysia. Contemporary issues in Malaysia Psychology. Malaysia: Thomson.

Unit Pengurusan Universiti, Kementerian Pengajian Tinggi (2011) Kemasukan pelajar sesi 2011/2012. Laman web rasmi kemasukan IPTA Bahagian Pengurusan kemasukan Pelajar, Jabatan Pengajian tinggi (KPT). http://upu.mohe.gov.my/upuphp

Unit Psikologi dan Kaunseling KKM (2011). Statistik Pegawai Psikologi KKM 2011. Ketua Profesion Pegawai Psikologi KKM

Zafar Afaq Ansari, Noraini M.Noor \& Ambar Haque (2005). Contemporary issues in Malaysia Psychology. Malaysia: Thomson 